\title{
Dan DONG (D)
}

Beijing Foreign Studies University

dongdan@bfsu.edu.cn

\section{Yuwei TAN D}

Beijing Foreign Studies University

ivatan@foxmail.com

\section{CHARACTERISTICS OF FOREIGN LANGUAGE EDUCATION IN ITALY AND IMPLICATIONS}

\section{FROM THE PERSPECTIVE OF NATIONAL FOREIGN LANGUAGE CAPACITY}

ABSTRACT This article reviews foreign language education in Italy using a national language competence-oriented evaluation approach. Foreign language education is at the heart of the acquisition component of language planning, and assessing foreign language education from the perspective of the purpose of language policy, i.e. the promotion of national language competence, which refers to the sum total of the government's ability to deal with all language-related issues of strategic interests and allows for a more direct application of language planning theory. Based on the theoretical framework of National Foreign Language Capacity and acquisition planning, this study presents a detailed analysis of the characteristics and problems of Italian foreign language education policy, taking into account its 'rationality', 'coverage,' and 'influence, which are three interrelated indicators that allow for a comprehensive and specific assessment of national foreign language competence. By revealing the inadequacies of Italy's national language proficiency system, the author intends to provide an insight into the gap between the effectiveness of policy formulation and implementation in foreign language education in Italy and to suggest some widespread problems in foreign language education that are similar to those in China.

Keywords: national foreign language capacity, foreign language education, acquisition planning, education in Italy, language policy and planning 


\section{INTERRELATED THEORETICAL FRAMEWORK OF FOREIGN LANGUAGE EDUCATION}

Although human language planning has a lengthy existence, it has only been developed as a professional discipline since the end of the second world war, with the most influential theoretical frameworks proposed by scholars such as E. Haugen (1982), ${ }^{1}$ R. Cooper (1989), ${ }^{2}$ B.H. Jernudd (1971), ${ }^{3}$ R.B. Kaplan and R.B. Baldauf Jr. (2003). ${ }^{4}$

According to Cooper's definition in Language Planning and Social Change, language planning is divided into three categories: corpus planning, status planning, and acquisition planning, ${ }^{5}$ of which this study focuses on the last category. In Language Planning and Social Change, Cooper points out besides that the effectiveness of language policy and planning (LPP) is largely determined by language education.

Status planning and corpus planning without acquisition planning will not achieve the objectives. And acquisition planning is responsible for the implementation of status planning and corpus planning. Thus, for example, once the role of a language in public life and its specific linguistic forms have been defined by policy-makers, language acquisition is organized by educators. ${ }^{6}$ The coordination of the three factors is evident in language planning.

Recent developments in critical and postmodern theories in the social sciences have entered the study of LPP, introducing a new perspective and focus. While the quality of foreign language education determines the outcome of language acquisition planning, and while specific assessment of foreign language education in schools, as the main venue for the provision of foreign language education, can help to generate instructive feedback on the other two types of planning, the author believes that national foreign language competence-oriented assessment is a re-examination of LPP research and has the following advantages over a purely acquisition planning perspective:

1. LPP theory is complex and its objectives are diverse and may even be contradictory, as E.H Jahr points out; the very act of language planning can lead to language problems and language conflicts.

2. The three categories of language planning are closer to methods than to outcomes, as Cooper points out. Language policy sometimes appears as a synonym for language planning but more often it refers to the goals of language

E. Haugen, The Implementation of Corpus Planning: Theory and Practice, Berlin 1982.

R.L. Cooper, Language Planning and Social Change, New York 1989.

3 B.H. Jernudd, J. Rubin, Can Language be Planned?: Sociolinguistic Theory and Practice for Developing Nations, Honolulu 1971.

4 R.B. Kaplan, R.B. Baldauf Jr, Language and Language-in-Education Planning in the Pacific Basin, New York 2003.

5 R.L. Cooper, Language..., pp. 31-33.

6 Ibid., p. 161.

7 E.H Jahr, Language Conflict and Language Planning, Berlin 1993, p. 1. 
planning. ${ }^{8}$ And the ultimate aim of the language policy is to improve national language capacity, which is a more direct and effective way of evaluation.

3. The evaluation system for language proficiency includes and redefines the different types of planning.

Regardless of the type of language planning, in nearly all cases the language problem does not exist in isolation from the region or nation but is directly associated with its political, economic, scientific, social, cultural or religious situation," which is intrinsically related to a nation's capacity to deal with linguistic-related issues. The term 'National Language Capacity' (NLC) indicates a component of both soft and hard power of a country, and is highly related to the national security in different areas, including politics, territory, military, economy, culture, society, science and technology, information, ecology, and resources. The NLC was first proposed at the end of the Cold War by American scholars Brecht and Walton and defined as the ability of the country to respond to demands for competencies in particular languages for whatever reason, including the ability to create instruction in languages not currently or generally offered..$^{10}$ The concept was subsequently introduced to China in 2011 and immediately attracted a great deal of attention from Chinese scholars.

In 2016, Wen Qiufang, professor at Beijing Foreign Studies University and researcher at the China National Language Proficiency Development Research Centre, inspired by the thinking of American scholars, pointed out the executive subject and scope of application of National Language Capacity, explaining that as the language competence is needed by the government to deal with matters involving national strategic interests at home and abroad, and in this regard identified five dimensions as the evaluation indicators for national language capacity, namely, management, monitoring, innovational, productive, and expanding.

In light of the continuing changes in China's national context, the practice of building national language capacity in China and the United States, and in order to better meet practical needs, Professor Wen Qiufang redefined national language capacity in 2019 as: the government's ability to use language to deal with all matters related to national interests. The original five dimensions have been consolidated into three: national language governance capacity, national language core capacity, and national language strategic capacity. ${ }^{11}$

In this regard, the national language strategic competence is a pillar for the country's foreign reform and opening up, safeguarding national sovereignty, shaping the national image, and enhancing the country's international status, and it contributes to the building of core competencies. National strategic language capacity covers four

R.L. Cooper, Language Planning and Social Change, New York 1989, p. 26.

$9 \quad$ F.X. Karam, Toward a definition of language planning, in J.A. Fishman (ed.), Advances in Language Planning, The Hague 1974, p. 108.

10 R.D. Brecht, A.R. Walton, National Strategic Planning in the Less Commonly Taught Languages, Maryland 1993, p. 6.

11 Q. Wen, Developing a Theoretical Framework of National Language Capacity, Beijing 2019, pp. 60-61. 
dimensions: national foreign language education, international expansion of the national lingua franca, national foreign discourse representation, and control of national language resources. ${ }^{12}$

National foreign language competence is an important component of national strategic language competence, and is directly related to the country's need to reform and open up to the outside world, safeguard national sovereignty, shape the national image, and enhance the country's international status. ${ }^{13}$ Foreign language education not only affects the country's education system, but also its socio-economic development, and is related to 'whether the government can train talents in a large number of foreign languages with high quality to meet the country's needs in handling various international affairs. ${ }^{14}$

The capacity of national foreign language education to build and develop can be evaluated by three indicators: rationality, coverage, and influence. ${ }^{15}$ The three indicators are interrelated and provide a comprehensive and specific evaluation of the construction of national foreign language education in terms of its language offerings and educational effectiveness, the relationship between the needs of the nation and society and the inherent laws of education, and the role played by foreign language talents in important domestic and foreign affairs.

Italy and China, as representatives of two ancient civilizations of the East and the West, despite their different national contexts and ideologies, both place a high priority on foreign language education, and their educational outcomes present similarities in terms of situations and problems. The following paragraphs will analyze the characteristics and problems of Italian foreign language education policy at different levels from the standpoint of the country's language capacity, and make some suggestions from a Chinese perspective (see Fig. 1).

Fig. 1. LPP approaches integrated with NLC

\begin{tabular}{|c|c|}
\hline Status planning & $\begin{array}{c}\text { Officialization } \\
\text { Nationalization } \\
\text { Standardization of status }\end{array}$ \\
\hline Corpus planning & $\begin{array}{c}\text { Codification of language forms } \\
\text { Graphitization } \\
\text { Grammaticalization }\end{array}$ \\
\hline Acquisition planning & Educational institutes \\
& Mass media \\
Literacy and work \\
Social groups
\end{tabular}

Ibid., p. 62.

13 Q. Wen, "The Connotation of National Language Capacity and its Evaluation Indicators", Journal of Yunnan Normal University, vol. 48, no. 2 (2016).

14 Q. Wen, Developing..., p. 62.

15 Ibid., p. 66. 
National capacity to control language talent resources

National capacity to create language talent resources

National capacity for language technology development

National capacity to expand the international reach of the lingua franca
National capacity to manage language matters of strategic national interest

\section{GENERAL INTRODUCTION TO FOREIGN LANGUAGE EDUCATION IN ITALY}

Compulsory education in Italy covers students from 6 to 16 years of age and generally starts at the age of 6 . Primary school lasts 5 years, and secondary school lasts 8 years, generally divided into 3 years of lower secondary school and 5 years of upper secondary school, which are divided into the following three categories and can be further subdivided according to the specific content taught, the length of upper secondary school studies may vary according to the specific situation.

Lyceum, for those students who want to continue their studies at the university, is divided into specific fields of study (humanities, sciences, languages, arts) and generally offers theoretical studies, except for students studying traditional arts, where the professional studies generally last five years.

Technical Institute, which offers theoretical studies as well as professional practice (economics, management, tourism, science and technology, agronomy) and includes a 3-6-month internship, with a duration of five years.

Professional institutes, which are designed for specific fields of study (engineering, agriculture, gastronomy, technological assistance, handicrafts) and aim to teach students skills that will enable them to find a job. Some schools offer diplomas. The instruction usually lasts 3 years, but may be from 2 to 5 years.

According to the United Nations International Standard Classification of Education (ISCED), Italian compulsory education can be classified as ISCED1 (primary education), ISCED2 (lower secondary education), and ISCED3 (upper secondary education). Each stage has its own adapted policy for foreign language education, which is set by National Ministry of Education and University Studies of Italy, while the postcompulsory professional education is generally decided by the Regions themselves.

There has been a certain awareness in Italy of the benefits of developing foreign language education beginning from the level of the kindergarten, and although no explicit policy has been developed, the National Guidelines for the Curriculum (Indicazioni Nazionali per il Curricolo) issued with the Decree 254/2012 of Italian Ministry of Education contains recommendations to use the multilingual environment in which children live so that they can receive appropriate instruction and that they can become familiar with a foreign language in natural situations, conversations, everyday life and gradually become aware of different sounds, tones, and meanings. 
In addition to English, the teaching of another EU language is offered at the primary level of education in Italy, but it is only at the lower secondary level that the subject is included in the compulsory foreign language education program for Italian students, and the Guidelines has made it clear that another EU language in addition to English is required at the lower secondary level.

For students who have already acquired more mature grasp of a language, this is an opportunity to extend their language skills. This provision may date back 10 years to the Barcelona Conference initiative to improve the mastery of basic skills, in particular by teaching at least two foreign languages. ${ }^{16}$ And the following year, the Italian Education Act immediately followed suit, with the Law no. 53 of March 2003 stating that knowledge of at least one language other than Italian from among the EU languages is required. This was followed in 2004 by Legislative Decree no. 59 of the Ministry of Education, which explicitly requires that English be compulsory in all classes at the primary level (primary and lower secondary) from the first year of primary education onwards. The primary stage of education provides students with the opportunity to study English and one other European Union language, which encourages the development of multilingualism and fosters an intercultural perspective.

The objectives of the English language cycle are to achieve a level of proficiency equivalent to A1 in the Common European Framework of Reference for Languages (QCER) at the end of primary school and A2 at the end of lower secondary school.

It is clear that the European Union's multilingualism initiative has had a lasting influence on Italian foreign language education policy, but the extent to which it has been implemented needs to be considered in relation to the testing of students' foreign language skills.

In fact, the Italian Ministry of Education has a clear requirement for foreign language proficiency for high school graduates, which is B1 level in English (or, in a few cases, another language) at the end of the second year of high school and a B2 level at graduation, with a final requirement of B1 for the second [foreign] language, which is aimed at high school students with a relatively general (social science, economic and social) orientation.

At the end of primary education, the school checks the student's ability in the first foreign language (generally, English), and the second language (with the provision that students who decide to allocate their learning time of the second foreign language to strengthen their proficiency in English or knowledge of Italian do not need to take the exam for the second foreign language) plus Italian, and mathematics in the form of a written exam.

Once they have completed their secondary education, Italian high school students are required to take the Italian national exam (L'esame di Stato or L'esame di maturita) before entering university, and to take the corresponding foreign language proficiency test.

16 Comunicazione della commissione al consiglio, al parlamento europeo, al comitato economico e sociale e al comitato delle regioni, Commissione delle comunità europee, Bruxelles 2004, p. 7. 
Separately, students in language high schools do not choose the language of their foreign language and culture examinations; this language is determined annually by the Minister of Education by special decree.

The Italian national exam is divided into two parts: a written component and an interview. The written section is also divided into two parts. The first is an analysis of a historical, social, literary or artistic text and is designed to test the student's reading comprehension. The second part requires a written presentation and analysis of a given subject. The interview generally requires students to be able to talk about and apply, as far as possible, all the relevant knowledge they have acquired throughout their studies, and if CLIL teachers are involved in the examination board, the examination of foreign languages is naturally included in the oral examination process.

\section{RATIONALITY: INNOVATION BASED ON THE EU MODEL}

Rationality refers to 'whether the way foreign language talents are trained is in line with the inner laws and the needs of society. ${ }^{17}$ Italy has been following the European Union's lead in the development of programs for the training of foreign language education personnel, taking full advantage of the facilities offered by the EU for foreign language education, but also developing strategic axes of language development in line with national realities. Italy attaches great importance to the continuity of language learning and has developed a coherent system of foreign language education covering primary, lower secondary, upper secondary, and higher education. In terms of international cooperation and exchange, the best possible use is made of advanced teaching methods and ideas and of international resources.

The language education policies of the EU have had an important influence on Italian national foreign language education and it can be said that, to a large extent, the Italian national foreign language and culture education formation aims to fit into the framework proposed by the EU. For example, the European Summit in Barcelona in 2002 identified ' $\mathrm{M}+2$ ' (mother tongue + two foreign languages) as a foreign language learning objective for Union citizens, followed by the publication of several documents or action plans by the European Commission to promote foreign language learning and multilingualism.

The following year, Italy began to focus on national foreign language education from a legislative point of view, particularly for the EU languages. At the end of the $20^{\text {th }}$ century, the EU introduced the 'Content and Language Integrated Learning' (CLIL), which is a dual focused educational approach where an additional language is used for the learning and teaching of both content and language. ${ }^{18}$ And in 2015 Italy specified in Decree 107 that one of the priority educational objectives of schools is to optimize and improve students' overall language skills, particularly in Italian, English, and other EU languages, through the use of the CLIL method.

17 Q. Wen, Developing..., p. 65.

18 D. Coyle, P. Hood, D. Marsh, CLIL: Content and Language Integrated Learning, New York 2010. 
The CLIL model provide Italy with means of entering into social-cultural situations by allowing more contact with target language, reveling a distinctive orientation to communicative competence. Also, in 2000, China include the formation of interdisciplinary foreign language talents in its foreign language education planning, which has elements of the CLIL experience in it. The approach is in line with the requirements to combine the rules of natural acquisition process and socio-cultural needs, which is in conformity with the rationality.

In addition to following the EU's language policy, the Italian Act 400/97 has introduced the unique Progetto Lingue 2000 multilingual program (PL2000), which is also based on the EU language requirements in an innovative teaching model, with language learning recommendations and language proficiency requirements for different educational stages. Through EU funding, various experiments and teaching projects have been carried out in Italian schools at all levels to introduce EU languages into middle schools as secondary foreign languages and to expand the resources available for foreign language education at all levels, including pre-schools.

The project has refined the requirements of the approach to foreign language education by including the following areas as its core criteria:

1) homogeneous and small groups (15-20 students);

2) division of allotted annual learning hours into short modules;

3) use of new technologies.

It is also suggested that schools should provide students with access to language certificates that are accredited by international organizations.

Another important innovation is the Italian Education Act 139 of 2007, which set out the development of four strategic cultural axes (assi culturali) in the country, the first of which is the language axis (asse linguaggio), together with mathematics, science and technology, and social history axes. The four strategic cultural axes intersect with each other to create a three-dimensional construction of culture in both vertical and horizontal dimensions.

The specific requirements of the linguistic axis are:

1) to strengthen the ability to master the common language (Italian) at a deeper level as well as the ability to input and output;

2) to become proficient in at least one foreign language;

3) to strengthen the development of non-verbal forms of expression such as art and literature;

4) to make full use of multimedia information and technology languages.

The significance of the strategic linguistic axis lies in the all-round planning that places equal importance on the common language, foreign languages, non-conventional forms of linguistic expression, and multimedia language, where mastery of the common language is a key prerequisite for all communication and where deep mastery of Italian can be applied to the learning and use of all languages in learning situations that contribute to the understanding of the connotations of foreign languages and foreign cultures.

Proficiency in a foreign language helps the people of a country to understand the culture of another in a multicultural context and facilitates learning and working 
exchanges. Knowledge of art, literature, and other forms of linguistic expression helps to stimulate personal reflection and creativity, increases sensitivity to cultural heritage protection, and promotes citizens' awareness of the value of cultural heritage. The learning of multimedia information technology helps to enrich one's knowledge and learning tools, communication channels, and innovative methods of expression.

The strategic language axis is an innovation based on the European Union's foreign language education policy, presenting the country's requirements for foreign language personnel in a more three-dimensional and precise form, extending the language skills requirements to the level of cultural application, which is a major expression of the rationality of foreign language education policy in Italy. However, the implementation of the policy requirements remains a major challenge for Italian language education.

In parallel to the integration of the EU concept of foreign language education into the Italian education system, Italy has taken the initiative to respond to the EU's multilingualism programs and has actively participated in various international cooperation projects to improve the country's foreign language skills, taking into account the national context, for instance, the Socrates Program and the Leonardo da Vinci Program launched between the 1980s and 1990s.

The former is a comprehensive education program covering different stages of education in the EU, from early childhood to adulthood, and is aimed at strengthening all types of education, promoting and popularizing knowledge of EU languages, and enhancing educational cooperation and mobility of teaching staff. The latter, 'Leonardo da Vinci', is a regional cooperation program for the integration of vocational education and training in member states in the context of economic globalization and the internationalization of education.

It is worth noting that the Socrates Program involves a wide range of specific actions in different areas, including higher educational exchange programs for students and teachers of Erasmus and Erasmus Mundus (since 2014, the two programs have been merged into Erasmus+), and the program Progetto Lingua. These initiatives from the level of EU are extremely supportive and orientated for foreign language education in Italy.

\section{COVERAGE: MORE OPPORTUNITIES TO BE CREATED}

The coverage of national foreign language education refers to the number of countries, regions and fields that can be covered by the variety of language talents created through foreign language education, that is, the number of languages involved, the number of languages with which the world can communicate directly and the number of fields in which it can function. ${ }^{19}$

According to data from the Italian research agency, Statista's 2019 survey on foreign language learning in Italian high schools, English learners still account for the

19 Q. Wen, Developing..., p. 65. 
largest share of foreign language learning at $99.6 \%$, with French in second place and $16.2 \%$, closely followed by Spanish, which accounts for $14.8 \%$. The fourth place is taken by German with $9.9 \%$, while only a very small proportion of students study Rus$\operatorname{sian}(0.4 \%)$.

The almost absolute dominance of English is a persistent phenomenon in Italian foreign language education. And as early as 2009, the EU Commissioner for Multilingualism, Leonard Orban, raised doubts that Italian education was too heavily weighted towards English, but Maria Stella Gelmini, the then Italian Minister of Education, denied the so-called 'hegemony of English' and continued to emphasize the importance of this language on the job market.

However, in terms of proficiency in English, Italy does not perform at a satisfactory level among the EU countries. As shown in the English Proficiency Index survey, Italy's national English level remains 'moderate,' with an EF EPI score of 547, placing it in a low position 25 out of 34 European countries. Comparable high youth unemployment rates in Italy and Spain may be a consequence of a similar lack of English proficiency in both countries, since improving English fluency is closely linked to international cooperation opportunities.

The European Commission's 2017 Eurydice Report states that in 2014 about one ninth of students in Italy were able to study at least one foreign language in primary education. ${ }^{20}$ The data graph below shows that the requirement of 'compulsory study of one foreign language' from 2002 to 2016 has extended the age range it targets to the primary education level (Fig. 2).

This shows that Italy is indeed still working on the path of improving students' multilingualism and actively pursuing relevant policies. In terms of the effectiveness of multilingual education, among the three levels of education (primary, lower secondary and upper secondary), the proportion of students learning two foreign languages at the lower secondary level is the highest. Statista's data of 2018 showed Italy's highest average number of foreign languages learnt belongs to the lower secondary among the different levels, however even so, that number being 1.9, it does not fully meet the 'two foreign' languages required by the EU. The average number of foreign languages studied at primary level only amounts to 1 , while at upper secondary level it is 1.4 .

In the case of the 'compulsory two foreign languages' requirement, Italy has made the leap from 'no' to 'yes' from 2002 to 2016, but still falls short of many European countries (See Figure 3).

Only a three-year requirement was made for the study of two foreign languages. Italy now requires all students to study two foreign languages from the age of 11, but the requirement is no longer compulsory once students enter high school. At the upper secondary level, or ISCED3, schools in Italy have the autonomy to decide on the foreign languages to be taught in general secondary education, and in some high schools foreign languages, including English, are compulsory or optional.

20 Cifre chiave dell'insegnamento delle lingue a scuola in Europa, Edizione 2017, Rapporto Eurydice, Lussemburgo 2017, pp. 62-63. 
Fig. 2. Period during which learning a foreign language is compulsory in foreign language education in Italy, from 2002-2016

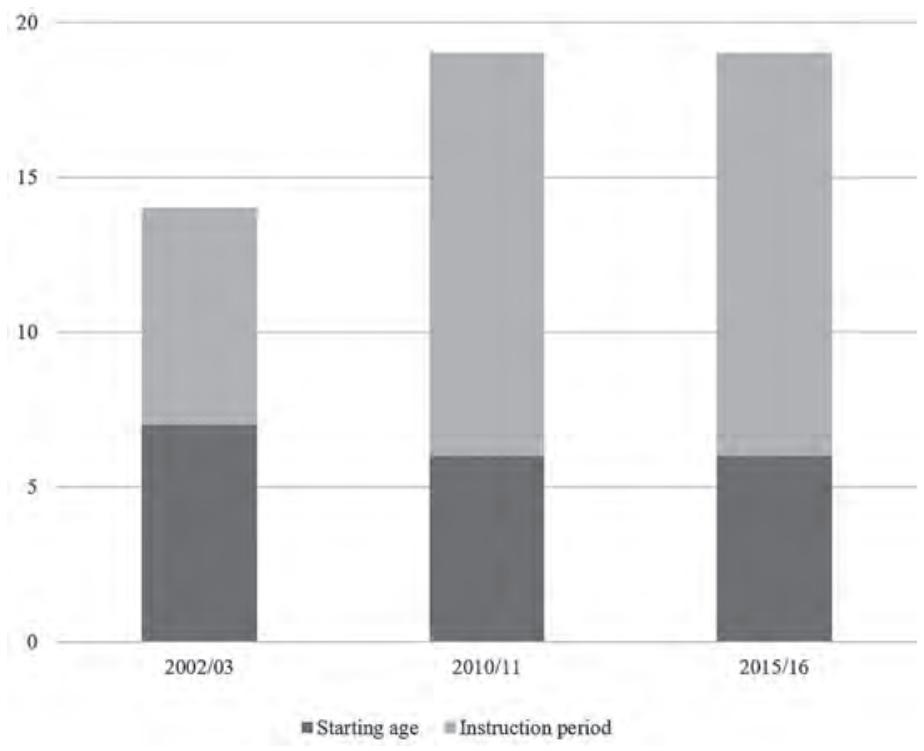

Source: Eurydice

Fig. 3. Period during which learning two foreign languages is compulsory in foreign language education in Italy, from 2002-2016

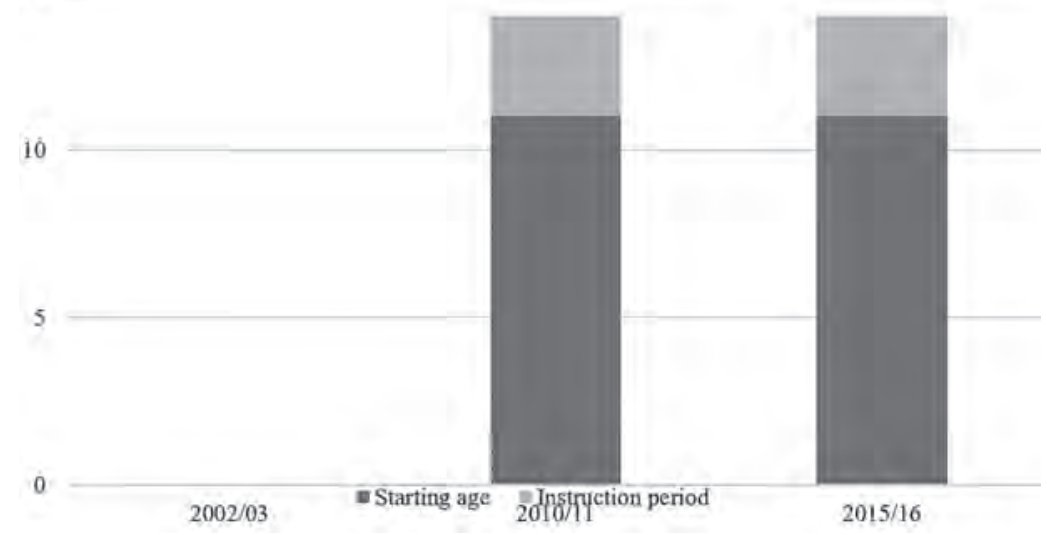

Source: Eurydice 
In 2016, for primary and general secondary education in Italy, English is compulsory at primary and lower secondary levels, while schools are allowed to offer the study of 16 other foreign languages, which vary according to the level of study. At the lower and upper secondary levels, French, German, and Spanish are optional, while at the upper secondary level they are not limited to the EU languages, but include Russian, English, Chinese, Arabic, Japanese, Portuguese, Modern Greek as well as Hebrew, Croatian, Serbian, Albanian, and Slovenian. In terms of the variety of foreign language education available, Italy is no less than any other European country.

Even though the coverage of foreign languages in Italy is expanding in line with the trend towards the strengthening of international cooperation, the dominance of English as 'lingua franca' in Italian foreign education in the context of globalization will not be changed in the short term, and this is not an exception for non-Anglo countries such as Italy. In fact, this is exactly what happens across the EU since English is the language that $97.9 \%$ of pupils learn in EU, with French and German learnt by $33.4 \%$ and $23.3 \%$, respectively. ${ }^{21}$

On the one hand, with English as the default language in the European Union and the most widely spoken language in the world, its proficiency determines a country's capacity of 'national foreign discourse representation' in the international scene and determines whether individuals can find adequate and favorable opportunities in global cooperation. However, if excessive emphasis is placed on to English in a country's foreign language education, it may deprive other languages of its attention and even jeopardize the national language.

Currently, Italy is by no means a highly Anglophone country in the European Union and has still a long way to go before considering the consequences of an overemphasized English language education and the improvement of the nation's English language proficiency. One of the issues is the low motivation of Italians to learn English and the low efficiency of teaching English, which are affecting the 'coverage' of implementation of foreign language acquisition policies. The Italian lower level of English proficiency compared to other EU states prevents it from operating on a European and world stage.

While it is true that Italy has its own strong cultural circle and its domestic daily life would hardly be affected even by a complete lack of English, being able to communicate well in 'international lingua franca' when appropriate is an expression of formal attitude universally accepted and reflects the capacity of national foreign discourse representation.

In the online survey of English Education in Italy of 2011 by Farahnaz Faez, only $79.3 \%$ of respondents believed that Italians were motivated to learn English (75\% at the primary level, $67.8 \%$ at the secondary level, and $90 \%$ at the post-secondary level), and as for the availability of English instruction in the public school system, only a half (51.8\%) of the respondents agreed that teaching methods used for English instruction

21 Eurostat, Dataset educ_uoe_lang01, Which are the Foreign Languages Studied Most Commonly? (\% of pupils at lower secondary level, 2017). 
at the primary and secondary levels are effective. Almost all participants (92.6\%) agreed or strongly agreed that teaching methods need to be improved or further developed. ${ }^{22}$

In accordance with the criteria of the number of languages involved and the number of languages with which the world can communicate directly, Italy's foreign language education policy has been developed with 'coverage' in mind, but the effectiveness of its implementation remains to be tested. The question of whether foreign language education can be translated into results that are relevant to the field in question requires the consideration of the 'influence' indicator.

\section{INFLUENCE: INSUFFICIENT ASSESSMENT MECHANISM}

'Influence' refers to the extent to which the foreign language personnel the country invests its resources in training can have a positive impact in the conduct of language affairs at home and abroad. In other words, whether they make a positive contribution to the country and to the development of humanity as a whole..$^{23}$ Although the requirements for foreign language education in Italy, from primary school to upper secondary, reflect a long-term, coherent, and scientific approach to foreign language education, there are major problems with foreign language education in Italy in terms of 'influence': for example, the relatively low number of non-English language learners, the lack of top-level foreign language personnel, the absence of Italy in international organizations, especially outside the EU, and the gap between the initial intentions of the policy and the actual results of its implementation. One of the reasons for this is the inadequacy of the assessment system for foreign language education, especially for noncompulsory languages in education.

Starting from primary school, English education in Italy is a natural initiation stage, with an overly 'natural approach' promoted in pedagogy, which starts with the learning of pronunciation and intonation patterns, based on the native language system to learn the elements of the new language, and then gradually differentiates them in order to introduce a natural multilingual environment. This actually corresponds to the learning method promoted in Europe since the 1970s, the Communicative Language Teaching (CLT) approach. The definitions of CLT characterizes it as a theoretical approach to apply a communicative view of linguistic pedagogy, from syllabus designed to in-class activities and the behavioral patterns of teaching and learning.

However, in most of cases, teachers do not introduce grammatical rules until lower secondary school to build students' capacity to learn a foreign language systematically. This disregard for grammatical rules has led to foreign language teaching standards favoring fluency over accuracy and, therefore, in practice, to the poor performance of students. The Ministry of Education gives a reference of one hour of English per week

22 F. Faez, "English Education in Italy: Perceptions of Teachers and Professors of English", Education Canadienne et Internationale, vol. 40, no. 3 (2011).

23

Q. Wen, Developing..., p. 65. 
in primary school for the first year, increasing each year thereafter, but does not provide strict rules, only stating that the number of hours per week can be adjusted according to the type of class.

In 2003, the CLIL was introduced in the Italian school system through a reform law as an extension of the CLT. The merits of the new approach have already been described in the section on 'rationality', but it is also important to note that there were no regulations regarding language competency for CLIL teachers or students either on the European level or on the national level. ${ }^{24}$

Meanwhile, it is worth noting that even though CLIL has much to offer in terms of theoretical feasibility as an improved version of CLT, in terms of actual practice, its impact usually suffers from imbalances in regional development and the absence of standardized norms in teaching.

The 2012 study of teacher expectations for CLIL in Naples by Di Martino and Di Sabato and the report of CLIL pilot projects in Lombardy from 2001 to 2006 showed almost entirely opposite results. The first study noted that while the Ministry of Education, University and Research (MIUR) has presented a comforting picture, many teachers were actually ambivalent toward the reform, believing on the one hand, that Italy needs to start developing more opportunities for language education, but on the other hand, feeling insecure and unsure about the trainers involved in the implementation of compulsory CLIL. ${ }^{25}$ Nevertheless, in the case of the northern region of Lombardy, most teachers who participated in the CLIL activities had received specific CLIL training to getting involved actively. ${ }^{26}$

In order to exploit the 'influence' of CLIL fully, it is necessary to overcome regional imbalances, based on 'rationality' of the approach, which is not simply a question of teaching methodology, but also involves complex socio-economic and cultural factors. In the relatively developed North, it is possible to train teachers systematically, but in the South, where resources are relatively scarce, it is one of the most important issues to consider in order to maximize the effectiveness of foreign language education in line with local economic and social development.

Another controversial point concerns the prolonged time taken to start foreign language education. The lack of rigorous academic specifications in primary school and the small amount of foreign language lessons are a waste of the 'golden age' for the first round of foreign language education and contribute to the Italy' lack of proficiency in English and expression in the international cooperation.

This is further corroborated by the current state of higher education in Italy. The Italian Ministry of Education has different objectives for the training of university

24 C.M. Coonan, “CLIL in Language Teacher Training”, Studi di Glottodidattica, vol. 2 (2011), pp. 1-14.

25 E. Di Martino, B. Di Sabato, "CLIL implementation in Italian schools: Can long-serving teachers be retrained effectively?" Latin American Journal of Content and Language Integrated Learning, vol. 5, no. 2 (2012).

26 Progetto Lingue Lombardia, Le esperienze di CLIL negli istituti scolastici della Lombardia 2001-2006: Rapporto di monitoraggio. Ministero della Pubblica Istruzione: Ufficio Scolastico per la Lombardia: ALI-CLIL, 2007. 
students in foreign languages, which is in conformity with the provisions of the Ministerial Decree 270/2004. Literature students need to have 'a complete command of at least one EU foreign language in written and spoken form.' The problem is that the decree does not specify the exact level of language proficiency or even link it to the Common European Framework of Reference for Languages (QCER), but only uses a vague requirement of 'complete mastery.'

Students in the science, technology and chemistry, information technology, and natural environment science and technology streams are required to be able to use at least one EU foreign language effectively, both orally and in writing, and to be able to communicate information in general, adapted to the needs of a given situation.' The level of foreign language skills required here is 'effective use,' which is also fairly hazy.

For the third category of students in economic sciences and business management, the requirement is 'the ability to speak and write two foreign languages in the EU,' which is a legislative requirement for the basic foreign language skills of students in different fields. The original intention was to develop students' foreign language skills at different levels of proficiency. The results, however, are still far from what was intended.

In 2012, a survey ${ }^{27}$ of language teaching in non-language professions by Michele Daloiso, Associate Professor of Modern Languages at the University of Parma and a specialist in language education, collected data from internationally ranked Italian universities. The analysis showed that $67 \%$ of students entered university without the official language requirement or were not accredited, which is not in line with the requirement to be assessed in a foreign language as a compulsory part of high school education.

In addition, English continues to be a major component of foreign language study in Italian higher education, with data showing that $94 \%$ of the sample had 'taken a course in English during their three years of undergraduate study, with between 2 and 6 credits,' and that $56 \%$ of undergraduates graduated with a B1 level of English and 34\% with a higher level.

On the question of whether there is a foreign language course other than English, only $50 \%$ of the sample answered in the affirmative, with $17 \%$ being compulsory and $33 \%$ being optional.

The level of second language proficiency at the end of undergraduate studies is significantly lower than that of English, with $89 \%$ of students having a level of A1-A2 and $11 \%$ B1-B2. $88 \%$ of the sample chose French, Spanish or German as their second foreign language, with the exception of the University of Polytechnic of Turin, which also offers Chinese. Foreign language education at postgraduate level is relatively scarce compared to undergraduate education. Only $39 \%$ of students study a second foreign language, and only $11 \%$ of them take a compulsory second foreign language. The low priority given to foreign language education at postgraduate level is also reflected in

The survey was conducted among language students from non-language faculties in 14 Italian universities, as detailed in M. Daloiso, P.E. Balboni, La Formazione Linguistica nell'Università, Venezia 2012, p. 48 . 
the number of credits, with $45 \%$ of students claiming their credits do not include a language course.

It seems that the 'influence' of foreign language education in Italy is not as expected, which is directly related to the arbitrariness of the process and the lack of an effective assessment mechanism for foreign language proficiency. However, it is worth noting that the Italian language census and the European Union's survey of foreign language proficiency are important tools for Italy to grasp the resources of language talent and to improve the influence of foreign language education.

Some of the most important sources available to Italy are the European Union's education network Eurydice, the statistical office Eurostat, and public opinion survey agency Eurobarometer ${ }^{28}$ which has carried out a number of large-scale surveys on foreign language education across the education systems of the EU member states. These resources provide the basis for national language policies by offering reliable data on language education and language acquisition, but at the same time they fail to collect consistent and accurate data from year to year. In another case, ISTAT, the Italian $\mathrm{Na}$ tional Institute of Statistics, conducts the Indagine dei cittadini e del loro tempo libero questionnaire every five years. This survey is designed to provide a more detailed and comprehensive questionnaire on language learning, which is helpful in understanding the effectiveness of citizens' foreign language learning, but there still remains the problem of its incomplete implementation.

On the one hand, Italy is expected to strengthen its national language proficiency census and improve its foreign language education policy in response to the problems that exist exclusively internally, rather than relying too heavily on the European Union. But on the other hand, it should also actively participate in international cooperation in order to gain experience and resources for the teaching of foreign languages and to adopt measures that benefit the country.

\section{A CHINESE PERSPECTIVE ON THE SIMILARITIES WITH THE PROBLEMS OF FOREIGN LANGUAGE EDUCATION IN ITALY}

The view of foreign language education from the perspective of national language capacity requires that acquisition planning must be situated in a social context and serve social goals (Lambert 1994). It is evident that foreign language education policy in practice often receives direct influence from the policy requirements of the times. From the beginning of the Cold War to the present, foreign language education in China has changed dramatically in line with the changing world landscape, starting with the replacement of English as the dominant language in Russian Studies, and with the promotion of global cooperation, especially in Chinese universities, which have continued to promote diversity in foreign language learning.

28 A special Eurobarometer survey was conducted in December 2000 to mark the European Year of Languages 2001: Gli europei e le lingue. 
It is also worth pointing out that languages other than English, such as Russian, Japanese, German, French, and Spanish, are gradually being included in China's college entrance examinations and in the teaching of secondary schools.

In 2008, a survey of foreign language education at the elementary level in China showed that there was a serious lack of diversity in the languages offered at this level, with $94 \%$ of foreign language learners in the country learning English, 7\% learning Russian, and 3\% learning Japanese. ${ }^{29}$ The majority study only one foreign language, and in the perception of many Chinese people, a 'foreign language' simply means English. In addition, there is a disconnect between the quality of foreign language education in China and the teaching evaluation system in English-speaking countries, ${ }^{30}$ and there is an urgent need for Chinese foreign language talents to expand their general professional studies to include cultural and international knowledge comprehension.

And while in recent years, in response to the Belt and Road Initiative, the variety of non-common language studies offered at universities in Chinese foreign language education has begun to increase significantly, this change in quantity has still not translated into an improvement in quality. One important point is that many non-common language courses are only offered at universities, resulting in students having no exposure to this language during their primary and secondary school years. While Italy has the European Union as a source of experience in foreign language education and a multilingual environment, China has had difficulty in finding a pattern that is compatible with its own situation, so the establishment of a policy with a scientific approach to foreign language education is even more of a challenge for China, which arguably faces numerous upcoming reforms in the planning of foreign language teaching and learning.

The solution to the imbalance in language distribution and quality of teaching requires substantial structural changes, which cannot be a reflexive response to the existing situation, but should be a prognosis of the potential needs of the country, so that foreign language education research institutions should regularly carry out research on domestic and foreign countries and needs. Italy and China, as representatives of two ancient civilizations, though differing in national contexts, also face similar problems, and this is an issue that needs to be addressed by China and Italy as well.

\section{BIBLIOGRAPHY}

Anno 2015: l'Uso della Lingua Italiana, dei Dialetti e delle Lingue Straniere, 2017, ISTAT: statistiche report.

Brecht R.D., Walton A.R., National Strategic Planning in the Less Commonly Taught Languages, Maryland 1993.

British Council, 2013-2017. Languages for the Future.

29 R. Wei, J. Su, "Survey and Analysis of Foreign Language Usage in Mainland China of 2008", Chinese Sociolinguistics, no. 2 .

30 British Council, 2013-2017. Languages for the Future. 
Cifre chiave dell'insegnamento delle lingue a scuola in Europa, Edizione 2017, Rapporto Eurydice, Lussemburgo 2017.

Coonan C.M., "CLIL in Language Teacher Training", Studi di Glottodidattica, vol. 2 (2011).

Comunicazione della commissione al consiglio, al parlamento europeo, al comitato economico e sociale e al comitato delle regioni, Commissione delle comunità europee, Bruxelles 2004.

Cooper R.L., Language Planning and Social Change, New York 1989, https://doi.org/10.1017/ CBO9780511620812.

Coyle D., Hood P., Marsh D., CLIL: Content and Language Integrated Learning, New York 2010, https://doi.org/10.1017/9781009024549.

Daloiso M., Balboni P.E., La Formazione Linguistica nell'Università, Venezia 2012.

Dell'Aquila V., Iannàccaro G., La Pianificazione Linguistica: Lingue, Società e Istituzioni, Roma 2004.

Di Martino E., Di Sabato B., "CLIL implementation in Italian schools: Can long-serving teachers be retrained effectively?" Latin American Journal of Content and Language Integrated Learning, vol. 5, no. 2 (2012), https://doi.org/10.5294/laclil.2012.5.2.9.

Faez F., "English Education in Italy: Perceptions of Teachers and Professors of English", Education Canadienne et Internationale, vol. 40, no. 3 (2011), https://doi.org/10.5206/cie-eci. v40i3.9187.

Hornberger N.H., Frameworks and Models in Language Policy and Planning Research, in T. Ricento (ed.), An Introduction to Language Policy: Theory and Method, Oxford 2006.

Jahr E.H., Language Conflict and Language Planning, Berlin 1993, https://doi.org/10.1515/ 9783110886580.

Karam F.X., Toward a definition of language planning, in J.A. Fishman (ed.), Advances in Language Planning, The Hague 1974, https://doi.org/10.1515/9783111583600.103.

Lambert R., "Problems and Processes in U.S. foreign language planning", The Annals of the Political and Social Science, vol. 532 (1994), https://doi.org/10.1177/0002716294532001004.

Pizzoli L., La Politica Linguistica in Italia: dall'Unificazione Nazionale al Dibattito sull'Internazionalizzazione, Roma 2018.

Progetto Lingue Lombardia, Le esperienze di CLIL negli istituti scolastici della Lombardia 2001 2006: Rapporto di monitoraggio. Ministero della Pubblica Istruzione: Ufficio Scolastico per la Lombardia: ALI-CLIL, 2007.

Wen Q., Developing a Theoretical Framework of National Language Capacity, Beijing 2019.

Dan DONG - lecturer and a Ph.D. candidate at School of European Languages and Cultures, Beijing Foreign Studies University. Her research interests include the Italian language and literature, and bilingual lexicography.

Yuwei TAN - graduate student of the Italian language and literature at Beijing Foreign Studies University. 